\title{
SUNESIOS VAN KURENE, HIMNE 6: VERTALING EN KOMMENTAAR
}

\author{
$J$ H Barkhuizen (Universiteit van Pretoria)
}

\section{Summary}

Following a translation of hymn 6 in Afrikaans, and a few remarks on its structure and nature, an analysis of this christological hymn is provided in the form of a commentary on each of the 7 strophes. Several "perspectives" occur throughout the hymn, namely that of praise (strophes 1 and 3), prayer (2/7), historical reference (4), liturgical context (5), while the hymn concludes with a cosmic perspective (6). Although the hymn lacks a clear philosophical and theological reflection, and is characterised by a soberness absent from hymns 7-8, which constitute with hymn 6 his christological trilogy, Synesius nevertheless shows forth the distinct nature of his poetry as hymn of praise. In the "historical" section of his hymn he uses the amazement of the Magi to contrast human wisdom with divine omniscience, while interpreting the gifts of the Magi allegorically in order to arouse his audience to participate in the praise of Christ, the Son of God and the virgin.

\section{Teks ${ }^{1}$ en vertaling}

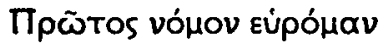

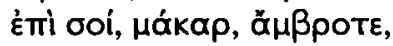

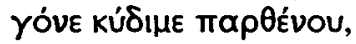

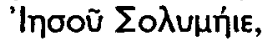

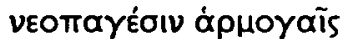

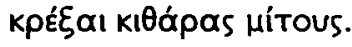

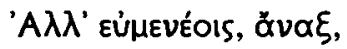

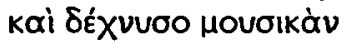

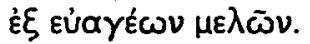

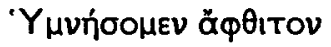

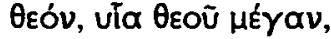
aíwvotókou matpòs Tòv koouoyóvov kópov,

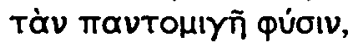
бофíav àmepeíoiov,

Tòv ÉTToupavíoss قeóv

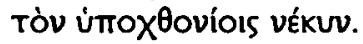

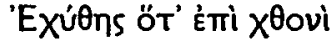

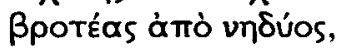

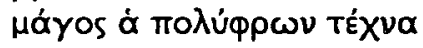

$1 \quad$ Lacombrade 1978:86-87. 


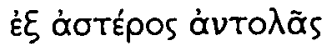

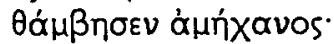

Tí Tò TIKTóhevov ßpéqos;

Tís ó kpuTtóuevos Azós,

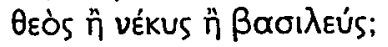

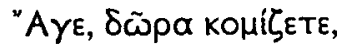

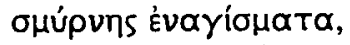

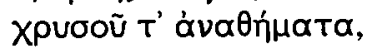

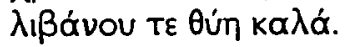

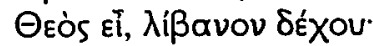

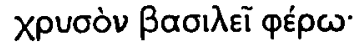

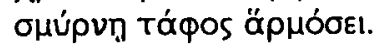

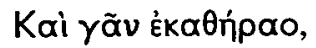
kai móvtıa kúpata,

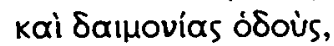

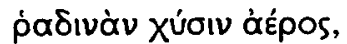
Kå̀ veptepíous HuXoús,

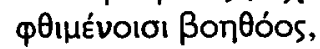

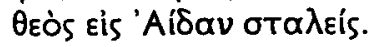

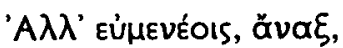

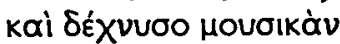

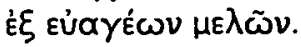

Ek was die eerste wat 'n melodie ${ }^{2}$ ontwerp het om tot $\mathrm{u}$ eer, o Geluksalige, Onsterflike, roemryke Seun van 'n maagd, Jesus van Jerusalem, ${ }^{3}$ met nuwe toonaarde ${ }^{4}$ die snare van my kithara te pluk.

Wees my dan ${ }^{5}$ goedgesind, o Vors, en ontvang die harmonie van my heilige liedere.

Ons sal die onsterflike

God besing, die magtige Seun van God, die Skepper van die kosmos, Seun van die Vader wat die eeue voortbring;

2 Of: "komposisie".

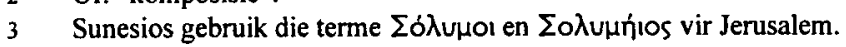

4 Of: "akkoorde".

$5 \quad$ ' $A \lambda \lambda$ ' (in die Grieks) dui hier op die gedagte van: al het ek eerste 'n nuutontwerpte vómos daargestel om $U$ te besing, is dit nogtans u guns wat my lied Godpassend maak. 
(en) sy alomteenwoordige $e^{6}$ natuur,

(en) sy onbeperkte wysheid;

Hy wat God is vir die hemelinge,

(maar) dooie (lyk) vir dié onder die aarde.

Toe U "uitgegiet" is op aarde

vanuit 'n sterflike moederskoot,

was die Magiërs in hulle kundige wetenskap'

verwonderd en stomgeslaan

voor die opkoms van 'n ster.

Wie was dié kind wat sopas gebore is?

Wie hierdie verborge God?

'n God of 'n sterfling ${ }^{8}$ of 'n koning?

Kom, bring julle geskenke, dodeoffers van mirre, sowel as gawes van goud, en pragtige offers van wierook.

$\mathrm{U}$ is God, ontvang die wierook.

Ek bring goud vir die Koning.

Die mirre sal gepas wees vir u begrafnis. ${ }^{9}$

En $U$ het die aarde gereinig,

en die golwe van die see,

en die weë van demone

- die dun lugstrome -

en die onderaardse holtes.

U was 'n hulp vir die gestorwenes,

toe $U$ as God na Hades gestuur is.

Wees my dan goedgesind, o Vors,

en ontvang die harmonie

van my heilige liedere.

\section{Uiteensetting}

Naas Gregorios van Nazianzos, is Sunesios (370-414) een van die belangrikste Christelike digters wat himnes in klassieke metra gedig het. Gebore uit 'n invloedryke familie in Kurene, het hy in Aleksandrië filosofie onder die bekende heidense vrouefilosoof, Hupatia, bestudeer, veral die Neo-Platonisme. In Aleksandrië is hy ook in 403 getroud met 'n Christelike vrou, en is hy tot die Christendom bekeer. In 410 is hy deur die inwoners van Ptolemais uitgenooi om hulle biskop te word, en is hy teen sy sin as biskop in die jaar 411 gewy. Sunesios is waarskynlik in 413 oorlede, en is

Letterlik: "wat met alles meng".

7 In die Grieks is TÉ Xva die onderwerp. Dit is egter beter om in Afrikaans die Magiërs self die onderwerp van die sin te maak.

8 Letterlik: "lyk".

9 Of: "graf". 
derhalwe die dood van Hupatia in 415 , deur die toedoen van 'n aantal fanatieke monnike, gespaar gebly. Hy is veral bekend vir sy nege himnes, wat nie oor die Christelike dogma as sodanig handel nie, en ook nie bedoel was as sang-liedere in die erediens nie (alhoewel dit nietemin wil voorkom of himnes 6-8 deel kon uitmaak van 'n liturgiese opset). Die rede hiervoor was natuurlik die feit dat hulle in die Doriese dialek en in klassieke metra (meesal anapestiese mono-, di- en trimeters) gedig is. Die Doriese dialek was uiteraard, maar ook die klassieke metra, vreemd op die oor en tong van die gewone Griekssprekende burger van die Hellenistiese wêreld, toe Grieks reeds oorgegaan het tot ' $n$ ritmiese heffing, gebaseer op die aksent, baie soos in moderne tale (kyk Mitsakis 1971).

Die nege himnes van Sunesios vertoon 'n eienaardige mengsel van NeoPlatoniese en Christelike idees. Baldwin (1985:44) beskrywe dan ook die algemene aard van die nege himnes as "a farrago of Neoplatonist and other images and ideas". Maar dit is veral himnes 6-8 wat 'n noue eenheid vorm, 'n groter kennis van en vertroudheid met die Christelike geloof vertoon (Quasten 3.113), en deur Lacombrade (1978:85 en 92) as Christologiese himnes omskrywe is-wat hy noem 'n "trilogie chrétienne". Die sesde himne handel oor die adorasie van die Wyse Manne en bied aan sy lesers of gehoor ' $n$ interpretasie van die Magiërs se geskenke. Sunesios merk in hierdie himne met trots op dat hy die eerste was om 'n liriese lied oor Christus te komponeer met begeleiding van die kithara.

Die doel van hierdie artikel is om dan kortliks die gedagtegang van himne 6 skematies aan te dui en enkele opmerkinge te maak oor die eieaard van die himne.

\section{Opbou en aard van die himne}

Himne 6 bestaan uit 7 strofes, waarvan 'n refrein-strofe (kyk nota 10) die derde en slotstrofe vorm. Elke strofe bied 'n eie "perspektief": (i) strofe 1 verwys na die digter se lied as lofkuns; (ii) strofe 2 en 7 bevat die gebedselement; (iii) strofe 3 herhaal die lofelement wat reeds in strofe 1 aangeraak word; (iv) strofe 4 het 'n historiese perspektief; (v) strofe 5 is liturgies van aard; en (vi) strofe 6 bevat die himne se "kosmiese" perspektief.

Die gedagtegang van die gedig, soos wat dit in elke strofe ontvou word, kan soos volg saamgevat word:

1. 1-6: Die digter wil deur hierdie nuwe metriese lied Jesus, die Seun van 'n maagd, besing.

2. 7-9: Gebedsrefrein vir die goedgunstige ontvangs van die lied. ${ }^{10}$

3. 10-17: Die digter besing Jesus wat sowel Seun van die almagtige God is as God wat mens geword het.

4. 18-24: Die ster wat sy geboorte aangekondig het, het die Wyse Manne in hulle wysheid en wetenskap verwonderd laat staan.

10 Lacombrade (1978:85) verwys wel na die "skynbare" refreinkarakter ("apparemment un refrain"), maar deel nogtans 7-9 (=40-42) in by deel 1 en 6 respektiewelik. Soos in die geval van himne 8, die derde himne in hierdie trilogie, wat eweneens deur 'n refrein gekenmerk word, is dit beter om dié versreëls as aparte refrein in te deel. Die gebed word in 'n mate ook gereflekteer in

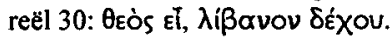


5. 26-32: Die mistieke simboliek van die offers van die Wyse Manne.

6. 33-39: Christus het die heelal gereinig van die demone en die gestorwenes in Hades te hulp gesnel.

7. 40-42: Gebedsrefrein $=7-9$.

Hierdie is 'n epifanie-himne (Lacombrade 1978:84), wat gekenmerk word deur 'n sterk mate van soberheid teenoor die soms sterk liriese karakter wat kenmerkend is van sommige van sy ander himnes, sodat Wilamowitz (1907:288) selfs praat van 'n "koudheid" wat in hierdie himne te vinde is. Opvallend is ook die afwesigheid in dié gedig van 'n beduidende filosofiese (metafisiese) en teologiese nadenke.

\section{Kommentaar}

Die openingsgedeelte (1-6) is net soos in die geval van himne 7.1-5 en 8.1-3 'n lofuiting op Jesus, die seun van 'n maagd. As sodanig volg dit die algemene openingspatroon van die Ou Testamentiese en Lukaanse lofliedere, maar wat ook dikwels in die profane Grieks-religieuse digkuns voorgekom het. Die woorde

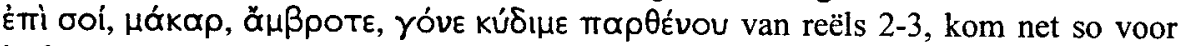
in himne 7.4-5, terwyl dit in himne 8 in reëls 1-2 in 'n soortgelyke vorm voorkom:

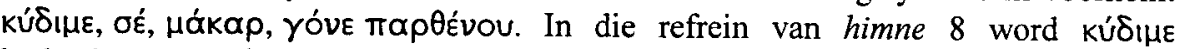

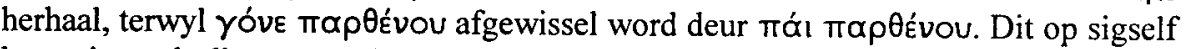
bevestig reeds die noue verband tussen dié drie himnes, soos hierbo aangedui.

Sunesios beskou sy lied as een gekomponeer in 'n harmonie wat hy as sy eie uitvindsel opeis. Inderdaad het ons hier ook te make met 'n tipe van oorspronklike telesilleion, wat ook in himnes 7 en 8 voorkom, dáár beide as katalekties en akatalekties, maar hier net as a-katalekties, waardeur die eerste lange deur twee kortes, en die laaste lange deur een korte vervang kan word: $\overline{-}-u-\backsim-\cup$ (kyk verder Keydel 1956:151-152).

Die gebed van Sunesios in die twee refrein-strofes $(2 / 7)$ om die goedgunstige ontvangs van sy lied, hou verband met 'n topos uit sowel die Grieks-profane digkuns as uit patristiese tekste. Hierdie topos bestaan in 'n "belydenis" (hier afwesig) van die digter se onvermoë om die godheid/God na behore te kan loof, en wat daarom bid (hier teenwoordig) om 'n goeie ontvangs van sy lied (kyk ook Epiktetos Diss. 1.16,19-21; Proklos van Konstantinopel, homilie 3.3 [PG 65.705D] en 22.1 [ed. Aubineau]; Romanos Melodos, himne 29.24.7-11 [ed. Grosdidier de Matons]; en ps.Afrem, Abraham Kidunaya 5, strofes 30-32). By Sunesios hou die gebed om guns direk verband met die feit dat hy 'n melodie/komposisie met nuutontwerpte toonaarde daargestel het, en dat God dit juis goedgunstig sal ontvang.

Die derde deel van die himne (10-17) neem die lofmotief weer eens op: die digter (en die gemeente-kyk hieronder) besing die Seun se onsterflike en skeppende

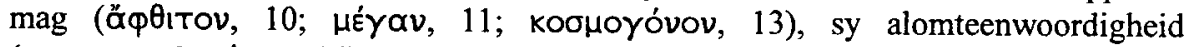

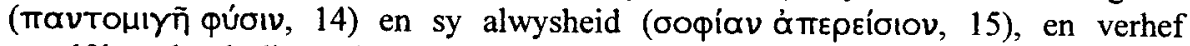
terselfdertyd ook die Vader se skeppingsmag (aiwvotókou matpòs, 12). Sunesios probeer om hierdie goddelike eienskappe te benadruk deur onder andere die gebruik van klankspel met veral $\alpha-(10,12,15), \mathrm{k}-/ \gamma-(11,12,13,14)$, en $\mathrm{u}-(10,11)$. 
Hierdie goddelike eienskappe, veral die alwysheid van God, word in die vierde, die historiese gedeelte (18-24), gekontrasteer met die wysheid van die Magiërs, waardeur die digter die sogenaamde verbasingsmotief as tegniek gebruik. In hierdie historiese deel beskryf Sunesios die geboorte van Jesus, met verwysing na die verdwaasheid en verwondering aan die kant van die Magiërs oor die verskyning van

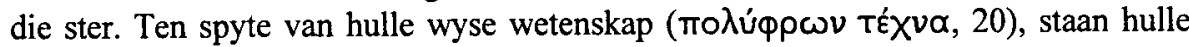

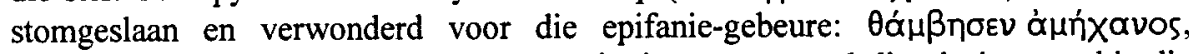

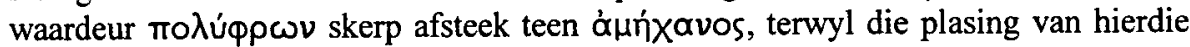
twee woorde alleen en saam in een reël, ook stilisties die kontras tussen God se wysheid en hulle kundigheid onderstreep. Wat die verbasingsmotief betref, Sunesios gebruik hierdie selfde motief ook in himne 8 waar die magte van die hemelruim vol

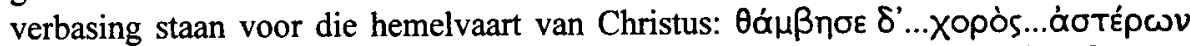
(8.34-35-kyk Barkhuizen 1993:268; en Homeros Il. 8.76-77: oi ठ்́ íóvTES

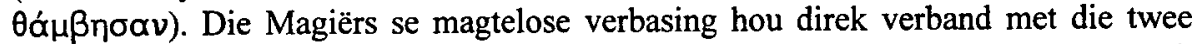
nature van Christus, 'n aspek wat in die sentrum van belangstelling in die Vroeë Kerk gestaan het: die Kind wat gebore is, is terselfdertyd God. Dit herinner aan Romanos Melodos, himne 10.10.1 en volgende, waarin vertel word dat die Magiërs verskrik staan by die aanskoue van die Kind Jesus omdat hulle besef dat Hy áyevea

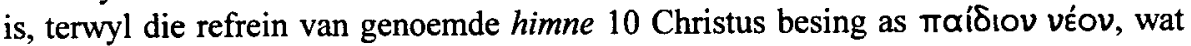

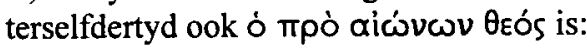

Die Magiërs het onmiddellik die kamer ingehaas;

by die aanskoue van Christus was hulle verskrik toe hulle

sy moeder en haar verloofde daar sien.

En in hulle vrees het hulle gesê: "Hierdie kind is sonder 'n menslike vader.

Hoe kom dit, o maagd, dat ons hierdie man sien

wat nou hier in jou huis staan?

Jou swangerskap was tog onbevlek?

Moenie dat Josef se teenwoordigheid skande oor jou werp nie.

Daar is talle nydige mense wat navraag doen oor waar gebore is nou 'n Kindjie, maar God voor alle eeue!"

Vir Sunesios is Hy egter ook die "verborge" God. Hy het sy godheid verberg in sy mensheid, wat ook tewens verklaar waarom $\mathrm{Hy}$, volgens die patristiese tradisie, die Dood kon mislei: in die voorkoms van 'n "lyk" (vékus), het Hy as God afgedaal (reël

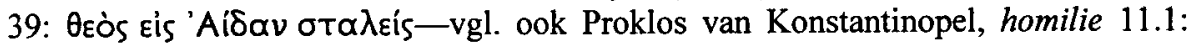

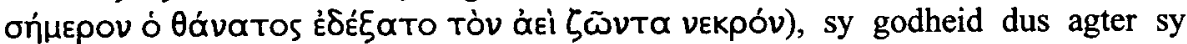
menslikheid verberg, en so die Dood oorwin (kyk hiervoor veral Grosdidier de Matons 1981:233-261 in Romanos Melodos). Die parallelle rym- en woordstruktuur van die twee reëls dien as stilistiese klem:

Tí Tò TıKTònevov ßpépos;

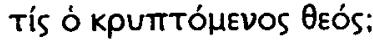

'n Verdere ooreenkoms tussen die derde en vierde deel is die soberheid en hardheid waarna aan die begin verwys is as besondere kenmerk van hierdie himne. In die derde 
deel is dit veral reëls 16-17 wat as twee parallel-gestruktureerde sinne sonder verbindingspartikel die aandag trek, en 'n skerp, "harde" kontras stel tussen die twee "nature" van Christus:

Tòv ĖToupavíoıs $\theta \varepsilon o ́ v$, Tòv úmox Oovíoıs vékuv.

Hy wat vir die hemelinge God is, is 'n blote lyk vir die onderaardse (kyk Proklos van

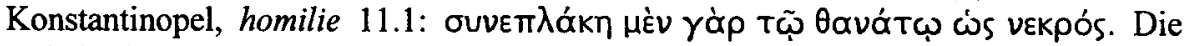
Bybelse bron is waarskynlik 2 Kor 13:4: "want al is Hy gekruisig in die swakheid van die mens, Hy leef uit die krag van God"). Laasgenoemde aspek, dat Hy as blote lyk in die onderwêreld aangesien is, het natuurlik aanleiding gegee tot een van 'n paar voorstellinge oor wat werklik in die onderwêreld gebeur het. Een opvatting was dat Hades Christus as blote menslike lyk aangesien het, Hom verslind het, en so die goddelike aas ingesluk het. Hy word dan verplig om Christus en die gestorwe mensdom uit te braak. Alhoewel Sunesios nie hierop ingaan nie, suggereer sy woordgebruik en kontras in hierdie twee reëls wel sy kennis met dié opvatting.

In hierdie vierde deel word die soberheid, waarvan melding gemaak is, verder

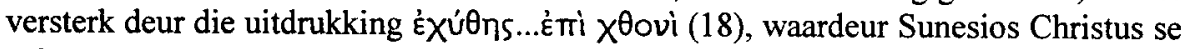
geboorte aandui. Hierdie uitdrukking verwys na 'n werklike geboorteproses in die antieke tye, soos dit in Eks 1:16 beskrywe word. " Dié gedagte is onder andere ook deur Proklos van Konstantinopel opgeneem in een van sy homilieë, waarin dit juis

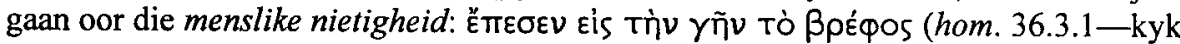
Barkhuizen 1996). Die "soberheid" van hierdie uitdrukking staan in skerp kontras met himne 8.13-14, waarin Sunesios ook na Christus se menswording of inkarnasie

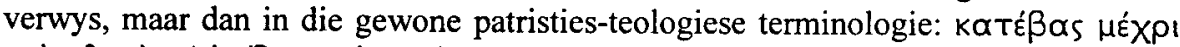

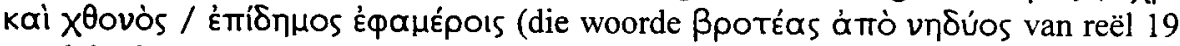

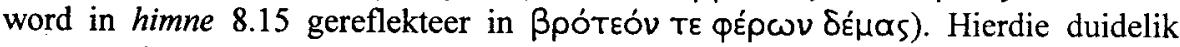
waarneembare trekke van "nugterheid" kan wees omdat Sunesios in hierdie himne bloot die ewe nugtere saaklikheid van die berig in Matt 2:11 wou nadoen. In elk geval is dit opvallend dat Sunesios die woord vékus herhaal in die vierde deel waar hy berig oor die verwondering van die Magiërs oor wie hierdie "kind is wat gebore is", wie hierdie "verborge God" is. Die vraag word gestel: is Hy dalk God of vékUs of koning? En alhoewel vékus in hierdie konteks waarskynlik met "sterfling" vertaal moet word, doen die herhaling van dié woord kort na reël 17, waar dit nie anders as met "lyk" vertaal kan word nie, opvallend voor, en versterk dit weer eens die sobere karakter van die himne.

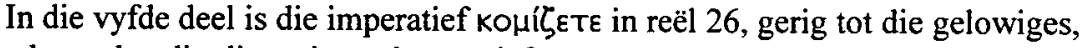
opvallend, omdat dit die enigste imperatief meervoud is wat in die himnes van Sunesios voorkom. Dit laat tog die vermoede ontstaan dat hierdie trilogie, anders as in die geval van sy ander himnes, wel binne 'n liturgiese konteks geplaas moet word, soos blyk uit die titel in Athous Vatopedinus 685 (V), 'n manuskrip uit die 13de eeu:

11 Vergelyk Barkhuizen 1996:19, nota 10: "Ex.1.16 refers to the birth-stool, which in fact were two stones (ha'obnajim)...The ancient custom was for women to kneel or sit on these stones at the time of their delivery...so that the child, when delivered, falls on the ground". 


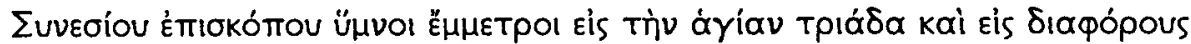

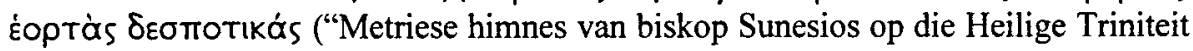
en die verskillende feeste van die Here"). Die tweede sinsnede verwys duidelik na liedere wat tydens die kerklike feesgeleenthede rondom Christus se lewe gebruik is.

Die allegoriese interpretasie van die geskenke van die Wyse Manne is in lyn met ander patristiese tekste. Afgesien van figure soos byvoorbeeld Irenaios ( $A d v$. haer. 3.9.2; $P G$ 7.870B-871A), verskaf die epifanie-himne van veral Prudentius (Cath. 12.65-72) 'n opvallende analogie:

\author{
agnosce clara insignia \\ virtutis ac regni tui, \\ puer o, cui trinam Pater \\ praedestinavit indolem: \\ regem deumque adnuntiant \\ thesaurus et fraglans odor \\ turis Sabaei, at myrreus \\ pulvis sepulchrum praedocet.
}

Herken, o Kind, die duidelike kentekens

van $U$ mag en soewereiniteit,

$\mathrm{U}$ vir wie die Vader 'n drievoudige

natuur vooraf bestem het:

die skat(te) en welriekende geur

van die wierook van Saba ('n landstreek in Arabië)

kondig $(\mathrm{U})$ aan as Koning en God,

maar die mirre-stof wys heen op die graf.

In die sesde deel vind ons ' $n$ motief wat hier kortliks aangeraak word, maar in veel meer uitgebreide vorm in himne 8 voorkom, naamlik Christus se kosmiese reinigings(= verlossings-) mag: hier die reiniging van die lug van demone, wat die domein par excellence van die demone is (kyk himne 1.89 en 8.31-33, asook Ef 6:12: "Ons stryd is...teen elke bose gees in die lug"), asook die verlossing van die gestorwenes, d.w.s. die oorwinning oor Hades (kyk himne 8.16-27; 31-37; en Barkhuizen 1993:266-271). Sunesios sluit die himne dus op 'n sterk toon af: in kontras met reël 17 (Tòv

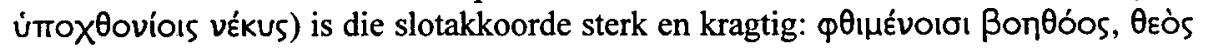

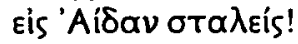

\title{
Slot
}

Ten spyte van die afwesigheid van 'n duidelik filosofiese en teologiese besinning, en die nugterheid van styl en toonaard, wat beslis verskil van die ander twee in die trilogie van Christus-liedere (himnes 7 en 8), wys Sunesios in hierdie himne nietemin op die eie aard van sy digkuns as lofkuns op Christus, die Seun van God en van 'n maagd. Terselfdertyd gebruik hy in die historiese deel van sy gedig die verbasing van die Magiërs om menslike wysheid te kontrasteer met Goddelike almag en wysheid, terwyl hy ook die geskenke van die Magiërs so allegories interpreteer dat hy daarmee 
ook sy mede-gelowiges aanspoor om deel te neem aan die "lof" op Christus. Die reinigings- en verlossingsaspek wat in die laaste deel (voor die slotrefrein) aangeraak word, vorm terselfdertyd 'n kragtige verkorte weergawe van die meer uitgebreide verwoording daarvan in himne 8.16-27.

\section{BIBLIOGRAFIE}

Baldwin, B 1985. An anthology of Byzantine poetry. Amsterdam: Gieben.

Barkhuizen, J H 1993. Synesius of Cyrene, hymn 8: A perspective on his poetic art. In Den Boeft, J, Van den Broek, R, Klijn, A F J, Quispel, G \& Van Winden J C M (eds.), Early Christian poetry: A collection of essays, 263-271. Supplements to Vigiliae Christianae 22. Leiden: Brill.

Barkhuizen, J H 1996. Proclus of Constantinople - Homily 36: On the brevity and futility of human life. Acta Patristica et Byzantina 7:1-20.

Grosdidier de Matons, J 1981. Romanos le Mélode. Hymnes IV. Paris: Beauchesne.

Keydel, R 1956. Zu den Hymnen des Sunesios. Hermes 84:151-162.

Lacombrade, C 1978. Sunésios de Cyrène. Tome I: Hymnes. Paris: Les Belles Lettres.

Mitsakis, K 1971. The hymnography of the Greek church in the early Christian centuries. Jahrbuch der Österreichischen Byzantinischen Gesellschaft 20:3149.

Quasten, J 1975. Synesius of Cyrene. In Patrology, vol. 3:106-114. Utrecht/Antwerp: Spectrum Publishers.

Wilamowitz-Moellendorff, U von 1907. Die Hymnen des Proklos und Synesios. Sitzungsberichte der königlich Preussischen Akademie der Wissenschaften 14:272-295. 